\title{
Design of Multi-band Microstrip Patch Antennas for Mid-band 5G Wireless Communication
}

\author{
Karima Mazen ${ }^{1}$ \\ Department of Electronics and Computer \\ Thebes Higher Institute for Engineering \\ Maaddi, Cairo, Egypt
}

\author{
Ahmed Emran ${ }^{2}$, Ahmed S. Shalaby ${ }^{3}$, Ahmed Yahya ${ }^{4}$ \\ Department of Electrical Engineering \\ Al-Azhar University, Nasr City \\ Cairo-11371, Egypt
}

\begin{abstract}
Recently, the best antenna structures have considered microstrip patch antenna due to their simple construction, low cost, minimum weight, and the fact that they can be effortlessly integrated with circuits. To achieve multiband operation an antenna is designed with an etching rectangle and circle slot on the surface of the patch to achieve multi-band frequency capabilities in mid-band 5G applications. Inset-fed structure type of fed of all antenna printed and fabricated on the brow of the Rogers RT5880 substrate. Then, prototype structures of the microstrip patch antenna were acquired during the design process until achieving the desired antennas. The antenna_1 achieved tri-band characteristics covering the WiMAX band including $2.51-2.55 \mathrm{GHz}$, WLAN, and S-band including 3.80 3.87 GHz and $\mathrm{C}$-and $\mathrm{X}$-band including $6.19-6.60 \mathrm{GHz}$. The antenna_2 gives dual-band characteristics covering C-band and $\mathrm{X}$-band including $(6.72-7.92 \mathrm{GHz})$ with a peak under $-45 \mathrm{~dB}$ suitable for mid-band 5G applications. High impedance bandwidth increases between (70 MHz-1.25 GHz) for wireless applications. The proposed microstrip patch antennas were simulated using CST MWS-2015 and were experimentally tested to verify the fundamental characteristics of the proposed design, it offers multiple-band operation with high stable gain and good directional radiation characteristics results.
\end{abstract}

Keywords-Band-width; microstrip; multi-band; notch slot; rectangle slot; 5 G

\section{INTRODUCTION}

Generally, the microstrip patch antenna is an important component of communication systems that require characteristics such as compact size, lightweight, easy process of fabrication, and wide bandwidth. The microstrip patch antenna is primarily made of copper material or a perfect electric conductor (PEC). There are various types of geometries like a circular, rectangular, triangular, elliptical, square, ring, cone, etc. Nevertheless, the most commonly used shapes are rectangular and circular. The size of the patch antenna depends upon the substrate constant dielectric material (Er). A Higher substrate dielectric constant leads to the lower size of the antenna [1][2]. The $1 \mathrm{G} / 2 \mathrm{G} / 3 \mathrm{G} / 4 \mathrm{G}$ and Five generations (5G) introduce faster data rates, density connection higher, low latency [3]. Compact patch feeds square microstrip with right-angled isosceles Koch fractal antenna geometry on the edges is suitable for U-wide frequency band applications. The antenna is put on FR4epoxy, $(\mathrm{Er}=4.4)$ substrate with dimensions $60 \times 55 \times 1.59$ $\mathrm{mm} 3$. The antenna works at $4.3,5.0,6.1,7.4,8.9$, and 9.2 $\mathrm{GHz}$, this design is limited in bandwidth and gain, therefore required to strive to improve them [4]. Propose the patch antenna in the form of a Sierpinski fractal antenna, which can work in multi-band frequency, this design is limited in bandwidth and gain, therefore required to strive to improve them [5]. The designed microstrip antenna using CPW feeding technique, the microstrip antenna operates resonates at this is bands $0.45 \mathrm{GHz}$ for GSM, 1.35, 1.92, $2.57 \mathrm{GHz}$ for, WLAN, WiMAX, Walkie-Talkie. The antenna dimension is $46.32 \times 25 \times 1.6 \mathrm{~mm} 3$, substrate type is FR4 with $\mathrm{Er}=4.3$. The design is limited in bandwidth and gain, therefore required to strive to improve them [6]. The proposed microstrip is fabricated using an FR-4, the height of the substrate is 1.6 $\mathrm{mm}$, and $\mathrm{Er}=4.4$. The ground plane and substrate dimension are the same, i.e. $(70 \times 60 \mathrm{~mm} 2)$, the proposed microstrip antenna operates at desired frequencies 5.73, 1.8, 3.6, and 4.53 $\mathrm{GHz}$, which can be used for many applications of the wireless [7]. Design patch antenna for satellite applications and operating frequency at $15 \mathrm{GHz}$ with diverse slots cutting on microstrip antenna. The antenna achieving bandwidth frequency at $1.14 \mathrm{GHz}$, with $\mathrm{S} 11$ of $-30.6 \mathrm{~dB}$. The gain and directivity are 3.488 , and $3.544 \mathrm{~dB}$ respectively. The RT duroid material size $9.5 \times 8 \times 1.6 \mathrm{~mm} 3$ to design microstrip antenna with $\varepsilon r=2.2$ have loss tangent 0.0009 [8]. The microstrip patch is fabricated and tested on substrate FR-4 with size $70 \times 70 \times 1.6 \mathrm{~mm} 3, \varepsilon r=4.4$. The choice bands are designed at 2.478, 2.313, and $2.396 \mathrm{GHz}$, and they have -10 $\mathrm{dB}$ impedance bandwidths of 2.42, 2.14, and 2.50\%, respectively [9]. The microstrip patch antenna in the shape of the rectangle there is an array of L-slots and inverted them slot for multiband frequency is considered. The microstrip was designed for TM010 mode of frequency operation at $2.1 \mathrm{GHz}$. The configuration produced the best results at Penta frequency bands:1.48, 1.25, 1.8, 2.25, and $2.9 \mathrm{GHz}$. And they have -10 $\mathrm{dB}$ impedance bandwidth $3.4 \%, 3.2 \%, 3.33 \%, 4.3 \%$, and $3.1 \%$, respectively [10] All the design there is limited in bandwidth and gain, therefore required to strive to improve them. Design a simple microstrip antenna (UWB) for the wireless satellite. The design process is achieved in three steps. Firstly, a conventional antenna for $2.4 \mathrm{GHz}$ FR4 substrate with $\varepsilon r=4.4$ has been defined with dimensions of 50 $\times 55 \times 1.6 \mathrm{~mm} 3$. Bandwidth is achieving between (2- 9.7 $\mathrm{GHz}$ ) for different wireless applications [11]. Design microstrip a slotted pentagonal for multi-band applications. Designed on substrate material textile type with a dielectric constant is 4.4. Dimension size is $50 \times 50 \mathrm{~mm} 2$ and thickness $(\mathrm{h}=1 \mathrm{~mm})$. The resonate frequency at $4 \mathrm{GHz}$ with $\mathrm{S} 11$ is $31.84 \mathrm{~dB}$. The antenna is achieved more directivity of 2.932 
$\mathrm{dBi}$ and bandwidth from 2.85 to $9.30 \mathrm{GHz}$ [12]. Simulated and fabricated a rectangular patch is introduce designed for 915 $\mathrm{MHz}$ band applications includes ZigBee and Bluetooth. A printed antenna on FR-4 epoxy substrate with a small size 60 $\times 30 \times 1.6 \mathrm{~mm} 3$, with $\mathrm{Er}=4.4$. Achieving bandwidth from 902 $\mathrm{MHz}$ to $925 \mathrm{MHz}$ for the ZigBee band applications. The results of the simulation are radiation pattern directivity is $2.83 \mathrm{dBm}$, the gain is $2.73 \mathrm{dBm}$, and return loss is $-35 \mathrm{~dB}$ [13]. Design a novel broadband microstrip antenna printed on the FR-4 substrate with $\mathrm{Er}=4.4$. The simulated result of the patch gives four resonance frequencies at 1.59, 1.71, 1.81, and 1.986 GHz respectively, achieve a bandwidth of $29.6 \%$ [14]. The microstrip U patch antennas on substrate Alumina $60 \times 60$ $\times 12.5 \mathrm{~mm} 3$ with dielectric constant $\varepsilon \mathrm{r}=9.6$ for wireless communication. The improvement in antenna bandwidth is recorded at $20 \mathrm{MHz}$, and efficiency 99.6\%. The antenna operating frequency of the antenna is $3.8 \mathrm{GHz}(3.06-5 \mathrm{GHz})$, the antenna operates at single-band [15]. Design of a two-band patch using substrate PTFE, with a thickness of $0.8 \mathrm{~mm}$, the dielectric constancy is 2.55 . The patch antenna works at dualband $9.96 \mathrm{GHz}-12.84 \mathrm{GHz}$ and the bandwidth of the antenna is 270 and $550 \mathrm{MHz}$ respectively. The simulation result gives less value of $\mathrm{S} 11$ at $\mathrm{f} 1=9.96 \mathrm{GHz}$ and $\mathrm{f} 2=12.84$ is -33.6 and $-39.1 \mathrm{~dB}$ respectively. The bandwidth of the patch is $9.83 \mathrm{GHz}$ and $12.57 \mathrm{GHz}$ respectively [16]. Design of packaging of single antenna fed asymmetric slot-loaded triple-band patch antenna with LHCP and RHCP at two bands at (1.77645 GHz) for GPS L5 and (SDARS) at (2.320-2.345 GHz). The dimensions of the designed antenna $51 \times 52 \times 1.6 \mathrm{~mm} 3$ with substrate FR-4 material, and $E r=4.4$ [17]. Design a monopole antenna and implement them to operate at multi-band for 5G wireless communications and service. The antenna substrate dimension is $43 \times 38 \times 1.588 \mathrm{~mm} 3$ with dielectric constancy 4.4. The S11 parameter of the patch antenna is high than -20 $\mathrm{dB}$, and VSWR is $<2$ [18]. The design of the microstrip antenna is based on substrate RT/Duroid 5880 material with relative permittivity $\varepsilon r=2.2$. The patch designed and fabricated to operate in X-band is (8-12 GHz) and $60 \mathrm{GHz}$ frequencies. The microstrip antenna was printed on two substrate heights $(0.75-1.57 \mathrm{~mm})$ operate at $10 \mathrm{GHz}$ and, (0.127 - $0.254 \mathrm{~mm})$ for frequency band $60 \mathrm{GHz}$. Designing approach satisfied wideband and high gain antenna The antenna work at dual-band, but required to improve in bandwidth and achieve best reflection coefficient (S11) [19]. The microstrip patch was put on Duroid 5870 substrate h= $1.575 \mathrm{~mm}$, a Er of 2.33, and a dielectric loss of 0.0012, dualband to cover K-band applications [20]. Design patch antenna printed on Rogers RT5870 with $\mathrm{Er}=2.2$, and operate at 2.4 $\mathrm{GHz}$. The thickness of $0.787 \mathrm{~mm}$ for applications such as IEEE 802.15.1 Bluetooth, ZigBee, WiFi, wireless USB. Bandwidth achieved 25.5 MHz with return loss $-22.5 \mathrm{~dB}$. The design is limited in operating at single band, bandwidth, and gain, therefore required to strive to improve them [21].

In this work, a new design approach is objective to realize tri-band and dual-band MPAs appropriate for 5G wireless applications. Two Compressed simple microstrip patch antennas (MPAs) have been designed to cover multiple frequency bands for wireless applications. The design idea of these microstrip patch antennas is almost based on rectangular patch antenna and are namely rectangular patch etching two rectangle slots antenna (antenna_1), and notch rectangle patch etching circle slot (antenna_2). All these antennas are fabricated on Roger RT5880 substrate and they are built the model and analyzed by using the tool of the CST MWS simulator [22]. The CST simulated result exposes that the proposed microstrip antennas are designed to guarantee the best performance results. In terms of resonant frequency bands and directional patterns as well as high gains, improvement impedance bandwidth, and total radiations efficiencies. The rest content of this work is orderly as follows. In section II, discussion the configurations of the proposed patch and the analysis process for designing these microstrip patches are offered in detail. Section III and IV are review discussion the performance of the experimental and simulated results along with the features of the designed patch antennas and parametric study. Conclusions and future work are drawn in Section V and VI.

\section{Proposed Patch Antenna Design AND CONFIGURATION}

The simulation models of the two proposed design microstrip antenna structures are in Fig. 1(b) and Fig. 2(b), this is antennas, called the rectangular antenna etching two rectangle slots (antenna_1) etching on the reference (conventional) antenna (RA), and notch rectangle antenna with circle slot (antenna_2) by etching rectangle notch on corner of reference antenna and cutting circle slot on the middle of the patch antenna. The slot on the microstrip antenna is analyzed. The slot on the microstrip patch can be firm by using a duplicity relationship between the dipole and the slot [23] [24] [25]. The fabricated antennas are printed on the front side of the Roger RT5880 substrate. The height hs of $3.18 \mathrm{~mm}$, relative permittivity $\varepsilon r=2.2$. The constant $\varepsilon r$ of microstrip material should be between 2.2 and 12 for antenna designing [1]. The height of the substrate, $\mathrm{h}<<\lambda 0$ (where, $\lambda 0$ equal operating wavelength) [1]. The resonant frequency $\mathrm{fr}=2.4 \mathrm{GHz}$. The total substrate size (Ws $x \mathrm{Ls}$ ) of all antennas is $(94 \times 78 \mathrm{~mm} 2)$. Each patch structure of these antennas size of patch $(\mathrm{Wp}) \times$ length $(\mathrm{Lp})$ of $(47 \times 38 \mathrm{~mm} 2)$. The inset feeding type is used for the design because of its ease of fabrication in the PCB form, and easy matching with the existing system. The proposed microstrip antennas are configured to improve impedance bandwidth outcomes due to changes in substrate height and dielectric constancy. If the substrate height is increased the bandwidth of the antenna is also increased. This is because the bandwidth of the antenna is directly proportional to the substrate height. The feed width wf and length Lf, while the characteristic impedance is $50 \Omega$. A full ground plane is on the backside of the substrate material. Copper is used as the conducting material for patches and ground. The dimensions of the proposed microstrip antenna are calculated by using the well-known microstrip patch antenna formulas using this equation from (1) -(5) [1].

The width of the microstrip patch antenna $\left(W_{P}\right)$ is given by the following equation [1].

$$
W_{P}=\frac{c}{2 f_{r} \sqrt{\frac{\varepsilon_{r}+1}{2}}}
$$


Sub. $\varepsilon_{\mathrm{r}}=2.2, \mathrm{c}=3 \times 10^{8} \mathrm{~m} / \mathrm{sec}, \mathrm{f}_{\mathrm{r}}=2.45 \mathrm{GHz}$

The effective dielectric constant $\varepsilon_{\text {reff }}$ :

$\varepsilon_{r e f f}=\frac{\varepsilon_{r}+1}{2}+\frac{\varepsilon_{r}-1}{2}\left(1+12 \frac{h}{w_{p}}\right)^{\frac{-1}{2}}$

Effective length due to fringing effects:

$$
\Delta L=0.412 h \frac{\left(\varepsilon_{r}+0.3\right)\left(\frac{W_{p}}{h}+0.264\right)}{\left(\varepsilon_{\text {reff }}-0.2680 .3\right)\left(\frac{W_{p}}{h}+0.8\right)} h
$$

The effective length of the patch ( $\left.L_{\text {eff }}\right)$ :

$$
L_{\text {eff }}=\frac{c}{2 f_{0} \sqrt{\varepsilon_{\text {reff }}}}
$$

The actual length of the patch:

$$
L_{p}=L_{\text {eff }}-2 \Delta L
$$

To determine the ground plane dimensions length $\left(L_{g}\right)$ and width of the ground plane $\left(\boldsymbol{W}_{g}\right)$

$$
\begin{aligned}
& L_{g}=6 h+l_{p} \\
& W_{g}=6 h+W_{p}
\end{aligned}
$$

Where $\mathrm{W}_{\mathrm{p}}$ the width of the microstrip patch, $f_{r}=2.45 \mathrm{GHz}$ is the resonant frequency, $\varepsilon_{\mathrm{r}}=2.2$ is the dielectric constant of the substrate material, $h_{\mathrm{s}}=3.18 \mathrm{~mm}$ is the height of substrate material. The patch antenna $\mathrm{L}_{\mathrm{p}}=38$ is the length of the patch and $\mathrm{w}_{\mathrm{p}}=47 \mathrm{~mm}$ is the width of the patch. After many series of optimization by using CST simulator, then, the final parameters and the optimized value of the parameters are illustrated in Table I.

Reign successively conventional patch antenna (MPA) was designed founded and based on the equations (1) -(5) for resonating frequency at the proposed frequency. Initially, MPA is designed with the same geometrical parameters. The obtained CST simulated reflection coefficient $\left(\mathrm{S}_{11}\right)$ and radiation pattern realized gain of reference antenna (RA) shown in Fig. 1(a) or 2(a) and 3, an antenna is resonating at $f_{r}$ $=2.45 \mathrm{GHz}$ with $-10 \mathrm{~dB} \mathrm{~S}{ }_{11}$ impedance bandwidth $70 \mathrm{MHz}$ ranging from $(2.43-2.50 \mathrm{GHz})$ for $(\mathrm{WiFi})$, return loss is -23 $\mathrm{dB}$, and radiation pattern of the antenna. It is demonstrated from observations in Fig. 4 that the RA inset-feeding technique with a full ground plane has a better gain of $7.31 \mathrm{~dB}$ and, a boresight directional radiation pattern suitable for wireless communication application.
TABLE I. DIMENSIONS OF PROPOSED ANTENNAS

\begin{tabular}{|l|l|l|l|l|l|l|l|}
\hline Dimension & $\mathrm{W}_{\mathrm{s}}$ & $\mathrm{L}_{\mathrm{s}}$ & $\mathrm{L}_{\mathrm{f}}$ & $\mathrm{f}_{1}$ & $\mathrm{~h}$ & $\mathrm{G}$ & $\mathrm{w}_{1}$ \\
\hline $\mathbf{m m}$ & 94 & 78 & 32 & 12.7 & 3.18 & 1.0 & 3.4 \\
\hline Dimension & $\mathrm{t}$ & $\mathrm{l}_{1}$ & $\mathrm{l}_{2}$ & $\mathrm{D}$ & $\mathrm{l}_{3}$ & $\mathrm{w}_{2}$ & $\mathrm{w}_{3}$ \\
\hline $\mathbf{m m}$ & 0.07 & 17.5 & 25.20 & 18.4 & 9.60 & 19 & 7.35 \\
\hline
\end{tabular}

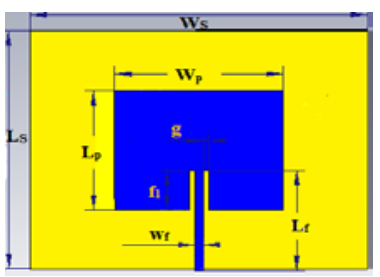

(a)

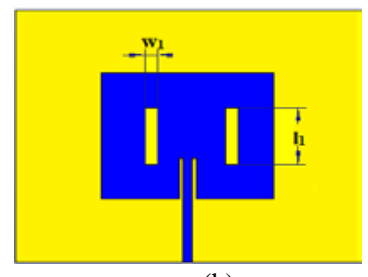

(b)
Fig. 1. The Proposed Microstrip Patch Structures, (a) AR (b) Antenna_1.

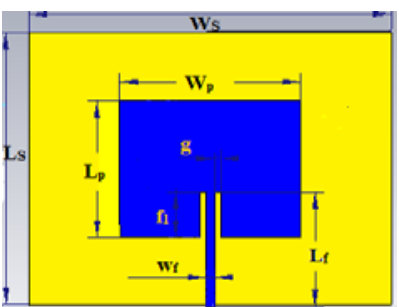

(a)

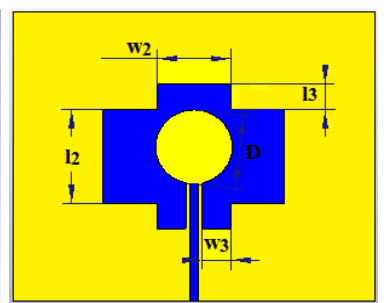

(b)
Fig. 2. The Proposed Microstrip Antenna Structures, (a) RA (b) Antenna_2.

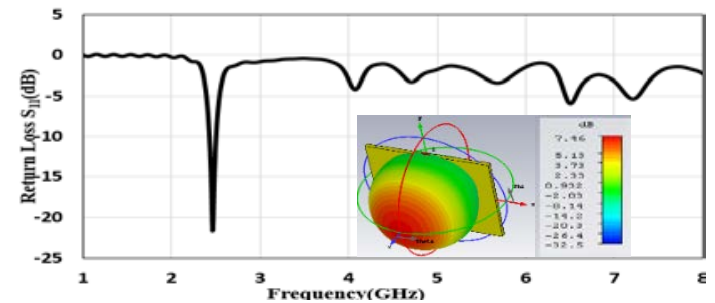

Fig. 3. $\mathrm{S}_{11}$ Plot and Radiation Pattern for the Reference Antenna.

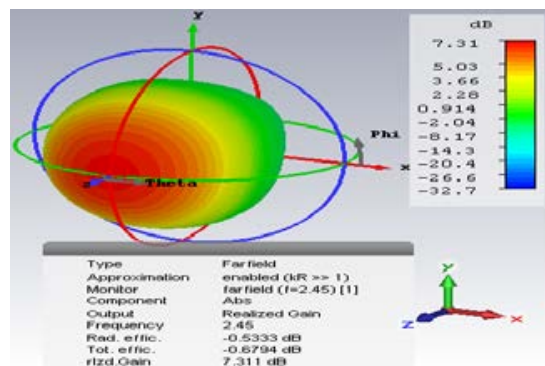

(a)

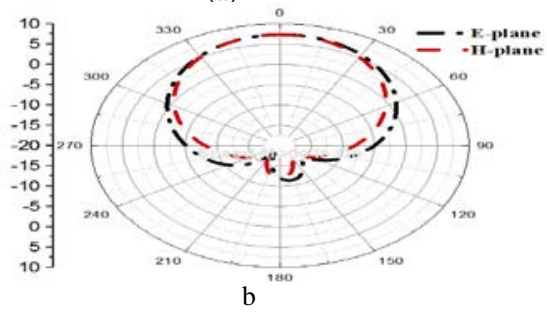

Fig. 4. Far-field Realized Gain Radiation Pattern of RA at 2.45 GHz. (a) 3D. (b) $2 \mathrm{D}$ in yz- and xz-plane. 
TABLE II. Microstrip PATCH ANTENNA (MPA) PERFoRMANCE PARAMETERS

\begin{tabular}{|l|l|}
\hline Parameter & Inset-feed with full ground plane \\
\hline$f_{r}(\mathrm{GHz})$ & 2.45 \\
\hline$f_{L}(\mathrm{GHz})$ & 2.43 \\
\hline$f_{H}(\mathrm{GHz})$ & 2.5 \\
\hline BW $(\mathrm{MHz})$ & 70 \\
\hline Gain $(\mathrm{dB})$ & 7.31 \\
\hline
\end{tabular}

Table II summarizes the main performance parameters of this reference antenna, lower and higher-frequencies, resonance frequency, bandwidth, and gain.

\section{Discussion OF Simulation Results}

After that, the procedure for microstrip patch antenna structures in the previous section is suggested for the proposed antennas for operating in the wireless communication WLAN, WiMAX, C- band, and -X band frequency ranges for midband 5G wireless applications [27]. The proposed design concept will be Verified by the main performance parameter results concluded to gain, reflection coefficient $\left(S_{11}\right)$, and current distribution on the patch as well as the radiation pattern directivity and realized gain.

\section{A. Reflection Coefficient}

The proposed microstrip patch antenna structures are realized in simulated of the CST Microwave Studio ver. 2015. Its time-domain solver is used to obtain these results. The reflection coefficient $\left(S_{11}\right)$ for the proposed microstrip antennas, antenna_1 and antenna_2 is discussed and investigated in detail. The results of the return loss of the whole prototype proposed antenna structures have been recapped in Fig. 5 and 6, shows the $S_{11}$ plot for intermediate antennas that belong to each type of the two proposed antennas. Observed that the antenna_1 covers tri-band characteristics, whereas the antenna_2 gives dual-band. The frequency bands of the proposed antennas can be summarized as follows:

1) Antenna_1: Cover WiMAX band $2.53 \mathrm{GHz}(2.51$ $2.55 \mathrm{GHz}, 1.5 \%)$ and WLAN/C-band and S band $3.86 \mathrm{GHz}$ (3.80 - 3.87 GHz, 2\%). C-band 6.45 GHz $(6.19-6.60 \mathrm{GHz}$, 6\%) for 5G application [26].

2) Antenna_2: Cover $C$ band and $X$ band for mid-band $5 G$ service [27], 6.92 and 7.707 GHz (6.72 - 7.92 GHz, 17.5\%).

Thus, these microstrip antennas cover the helpful frequency bands that useful for wireless communication.

VSWR results proposed microstrip antenna have been shown in Fig. 7. Their quantitative analysis in terms of $f_{r}, f_{l}$, and $f_{h}$, between RA and their proposed antennas, is listed in Table III. The realized gain respect to frequency for the proposed microstrip patch antennas at desired frequency bands is observed in the experimental result in section 3 . Then the gain of antenna_1 at the lower frequency band is the less one whereas it is the greater one in the high band.

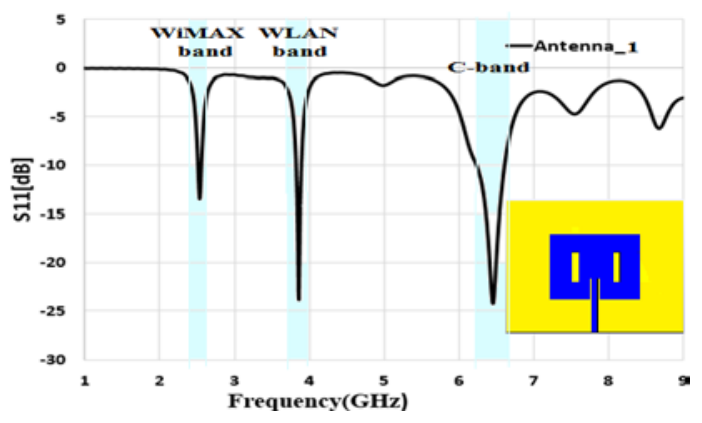

Fig. 5. Simulated Return Losses $S_{11}$ Curves for Antenna_1 at 2.53, 3.86 and $6.45 \mathrm{GHz}$.

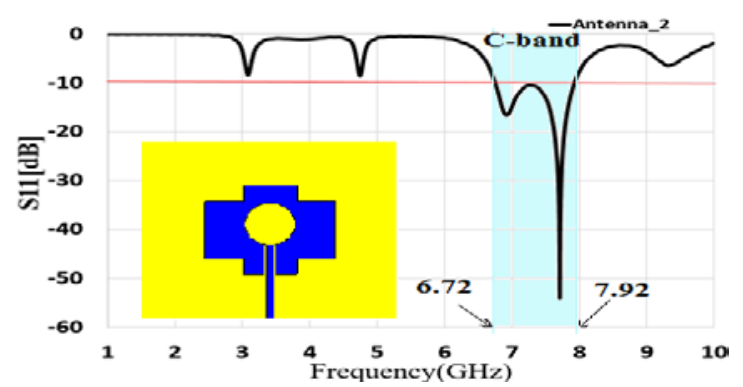

Fig. 6. Simulate Return Loss $\mathrm{S}_{11}$ Curve for Antenna_2 at $6.93 \mathrm{GHz}$ and 7.707 GHz.

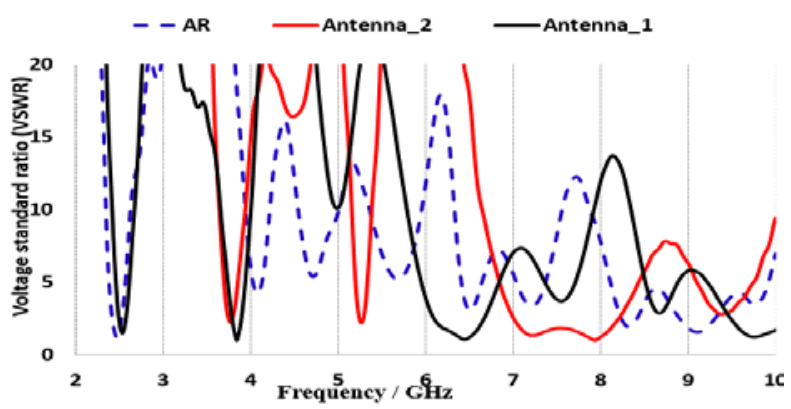

Fig. 7. Simulation VSWR for the Proposed Antennas

TABLE III. THE PROPOSED ANTENNAS TO RA COMPARISON FROM THE BANDWIDTH, (FL- FH), FR PERSPECTIVE IN (GHZ)

\begin{tabular}{|l|l|l|l|l|}
\hline Antenna & Band 1 & Band_2 & Band 3 & $\begin{array}{l}\text { B.W } \\
\text { (MHz) }\end{array}$ \\
\hline RA & $\begin{array}{l}(2.43-2.50), \\
2.45 \mathrm{GHz}\end{array}$ & ----- & ------ & 70 \\
\hline $\begin{array}{l}\text { antenna_1 } \\
\text { (Tri-band) }\end{array}$ & $\begin{array}{l}(2.51-2.55), \\
2.53 \mathrm{GHz}\end{array}$ & $\begin{array}{l}(3.803 .87), \\
3.86 \mathrm{GHz}\end{array}$ & $\begin{array}{l}(6.19-6.60), \\
6.45 \mathrm{GHz}\end{array}$ & $50,70,410$ \\
\hline $\begin{array}{l}\text { antenna_2 } \\
\text { (Dual-band) }\end{array}$ & ----- & $\begin{array}{l}(6.75-7.92), \\
6.92 \mathrm{GHz}\end{array}$ & $\begin{array}{l}(6.71-7.94), \\
7.707 \mathrm{GHz}\end{array}$ & 1250 \\
\hline
\end{tabular}

\section{B. 2-D and 3-D Radiation Pattern}

Fig. 8 shows the 2-D radiation pattern in terms of E- or yzplane and $\mathrm{H}$-or $\mathrm{xz}$-plane at band 1, band 2, and band 3 observed at Table III. It is observed from this figure that all antennas have a directive radiation pattern in $\mathrm{H}$-plane and $\mathrm{E}$ plane at the lower band $(2.53 \mathrm{GHz})$, and near to omnidirectional at all other middle and higher frequencies (3.86 GHz \& $6.45 \mathrm{GHz}$ ) bands. The radiation pattern in E-plan shown in Fig. 8(a) at $2.53 \mathrm{GHz}$ shows close to bidirectional nature with angular width (3) of 75.0 deg., and main lob 
directional 1.0 deg. Whereas, the radiation pattern at 3.87, 6.45 GHz shown in Fig. 8(b) and Fig. 8(c) shows close to omnidirectional nature with greater angular widths 59.2 and 31.6 degrees respectively. Besides, the main lob directional 4.0 and -5.0 degrees respectively. Therefore, the radiation pattern is changed from bidirectional to omnidirectional when the angular width is reduced.

Fig. 9 shows the 3-D radiation pattern for tri-band frequency (a) for $2.53 \mathrm{GHz}$, (b) $3.86 \mathrm{GHz}$, (c) $6.45 \mathrm{GHz}$.

Fig. 10 shows the 3-D radiation pattern for dual-band frequency (a) for $6.92 \mathrm{GHz}$, (b) $7.707 \mathrm{GHz}$.

The simulated results verified that the proposed antennas are achieved multi-band antennas. Table IV shows the simulation results of proposed antennas that have a good radiating element antenna, return loss less than $-20 \mathrm{~dB}$, good realized gain, VSWR is less than 2, and good impedance bandwidth.

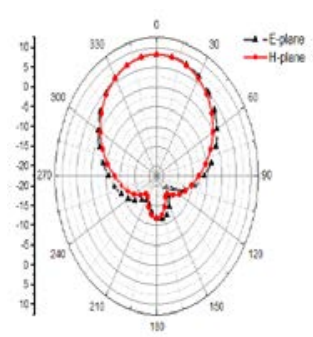

(a)

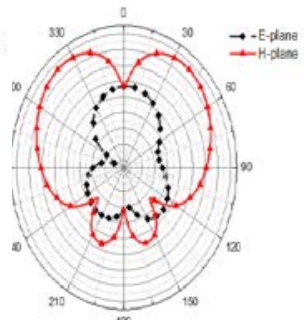

(b)

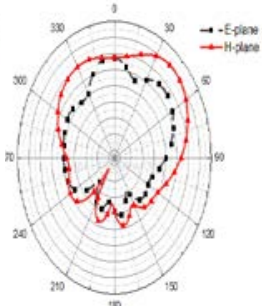

(c)
Fig. 8. Simulated E and H-plane for Antenna_1 at (a) $2.53 \mathrm{GHz}$, (b) 3.87 and (c) $6.45 \mathrm{GHz}$.

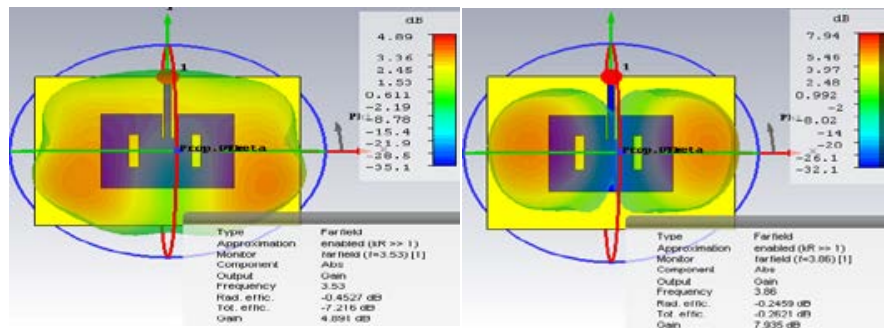

(a)

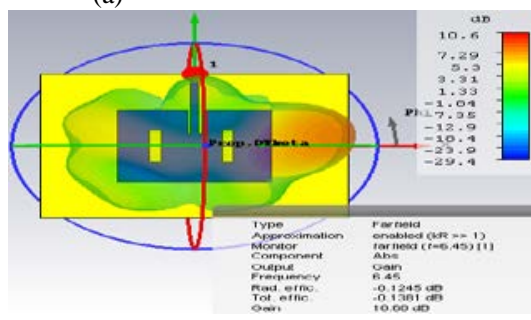

(b)

(c)

Fig. 9. 3D Radiation Pattern Gains of Proposed Antenna_1at (a) $2.53 \mathrm{GHz}$, (b) $3.86 \mathrm{GHz}$, (c) $6.45 \mathrm{GHz}$.

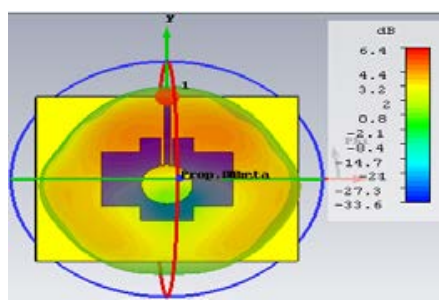

(a)

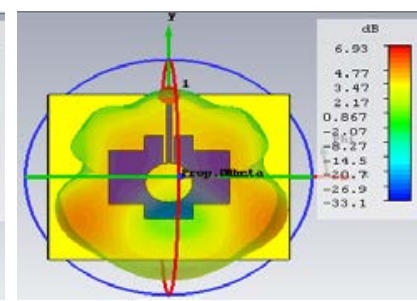

(b)
Fig. 10. 3D Radiation Patterns Gain of the Proposed Antenna_2 at (a) 6.92 $\mathrm{GHz}$, (b) $7.707 \mathrm{GHz}$.

TABLE IV. Simulated Multiband ANTENNAS -10 DB BANDWIDTH, GAIN, VSWR, DIRECTIVITY AND IMPEDANCE BANDWIDTH

\begin{tabular}{|l|l|l|l|l|l|}
\hline Results & \multicolumn{2}{|l|}{ antenna_1 } & \multicolumn{2}{l|}{ antenna_2 } \\
\hline $\begin{array}{l}\text { Frequency } \\
f_{r}(\mathrm{GHz})\end{array}$ & 2.53 & 3.86 & 6.45 & 6.92 & 7.707 \\
\hline $\begin{array}{l}\mathrm{S}_{11} \\
\mathrm{~dB}\end{array}$ & -13.38 & -23.86 & -24.26 & -16.92 & -55 \\
\hline VSWR & 1.4 & 1.1 & 1.1 & 1.3 & 1.4 \\
\hline $\begin{array}{l}\text { Dir } \\
(\mathrm{dBi})\end{array}$ & 8.34 & 8.22 & 10.73 & 6.38 & 7.28 \\
\hline $\begin{array}{l}\text { Gain } \\
\mathrm{dB}\end{array}$ & 8.18 & 7.97 & 10.6 & 5.56 & 6.22 \\
\hline B/W MHz & 50 & 70 & 410 & 1250 & \\
\hline
\end{tabular}

\section{Surface Current}

To analyze the effectiveness, of the proposed microstrip patch antenna, the higher modes make nulls and some side effects lobes this is due to the effect of the vertical and horizontal distributions current on the surface slotted microstrip antenna, as the operating band frequency increases. The surface current of antenna_1 shows in Fig. 11, and analyzed at frequency band in Fig. 11(a) shows the surface current distributed have mainly flowed throw feed line part and in a horizontal line on the patch at a lower frequency. However, the path and the direction of the density are entirely changed with the insertion of two rectangle slots. As shown in Fig. 11(b) the current distribution along with two rectangle slot more concentrated interior slot and exterior of two rectangle slot, mainly flows along feed line part. Thus, two rectangle slots modify the surface current distribution to generate resonance at $3.86 \mathrm{GHz}$. Fig. 11(c) shows the distribution mainly on the feed line part and inside two rectangle slots of the patch in relatively higher frequency (6.45 $\mathrm{GHz}$ ). From Fig. 11(d), it can be observed the surface current distribution the path, and the direction of the current are entirely changed with the insert of the circle slots. The current distributed concentrated throw feed line under an arc of the circle and its below. The current distributed interior edge of the circle and outside of circle slot, and less current density throw the notch. 


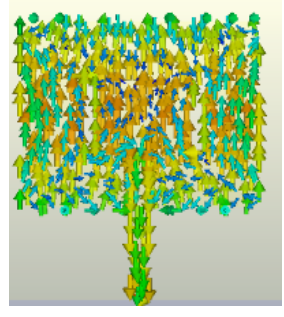

(a)

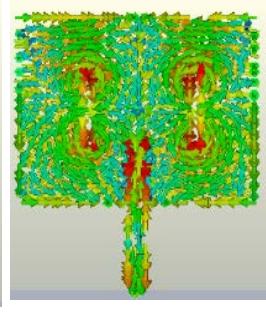

(b)

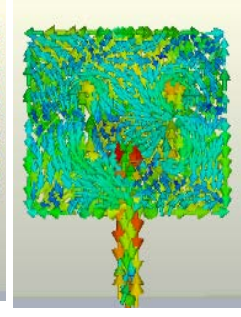

(c)

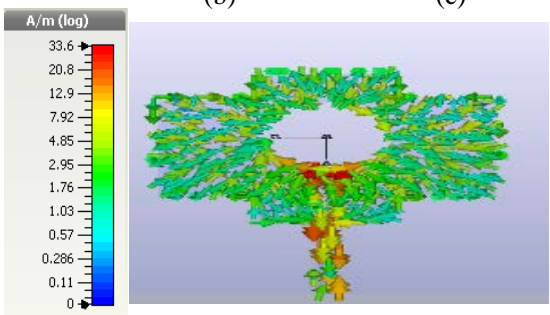

(d)

Fig. 11. Simulated the Current Distribution on Antenna_1 at, (a) $2.53 \mathrm{GHz}$, (b) 3.86 GHz, (c) $6.45 \mathrm{GHz}$ (d) The Surface Current on Antena_2 at $7.707 \mathrm{GHz}$.

\section{Parametric Study}

To reach up with a final design of acceptable performance worked at in-demand frequencies; dense simulations to test the insight of each antenna dimension and slots on its performance have been done using parametric sweep -timedomain solver CST simulator. The antenna_1 is optimized to operate at triple-frequency bands.

Fig. 12 shows the effects of variation on $\mathrm{S}_{11}$ characteristics, it indicates that the second resonant at 3.86 $\mathrm{GHz}$ is the most affected resonant, and its value increased $29.30 \mathrm{~dB}$ as $\mathrm{w}_{1}$ increased. While the first and third resonance for the patch itself; is not nearly affected. The rectangle length-shaped slot of antenna_1 is 11 changed in two rectangle slots to find its effect on antenna_1.

Fig. 13 shows the effects of variation in $l_{1}$ on $S_{11}$ characteristics. The center frequency of the second resonance is increased return loss is $-35.29 \mathrm{~dB}$ at $3.86 \mathrm{GHz}$ as $l_{1}$ increased while decreasing when the value $l_{1}$ decreases and the center frequency of the third frequency varies to change according to change the value of $l_{1}$. But first band resonance for the patch itself; is not nearly affected.

It can be observed that the impedance fractional bandwidth is wider for the third frequency band at a different value of $l_{1}$. Bandwidth $440 \mathrm{MHz}(6.17-6.61 \mathrm{GHz}, 6.87 \%)$ is resonating at $6.45 \mathrm{GHz}$ achieving a return loss of $-27.19 \mathrm{~dB}$ is obtained when $\left(l_{1}=18 \mathrm{~mm}\right)$. The effects result of variation in $l_{1}$ for impedance bandwidth and $\mathrm{S}_{11}$ are tabulated in Table $\mathrm{V}$.

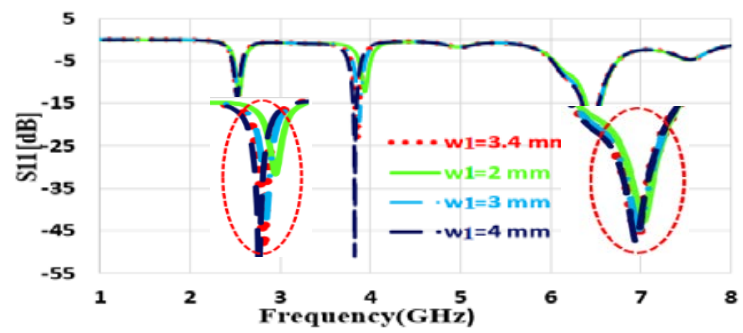

Fig. 12. Simulated $S_{11}$ for Antenna_1 with Variation of width of slot $\left(w_{1}\right)$.

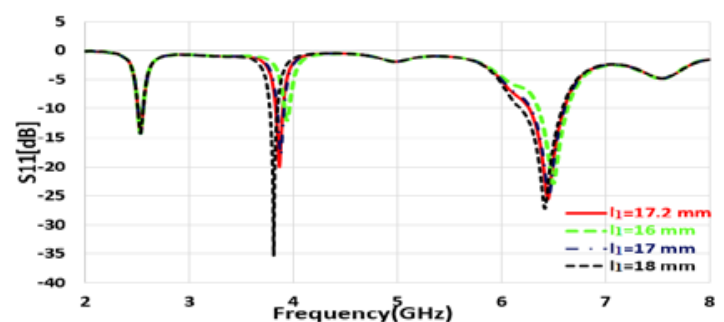

Fig. 13. Simulated $S_{11}$ for Antenna_1 with Variation of 11=16-18 MM.

TABLE V. COMPARATIVE RESULTS OF ANTENNA_1 VARIED LENGTH L1= 16 - $18 \mathrm{MM}$

\begin{tabular}{|l|l|l|l|}
\hline$l_{1}(\mathrm{~mm})$ & $\begin{array}{l}\text { Return } \\
\text { loss }(\mathrm{dB})\end{array}$ & $\begin{array}{l}\text { Triple } \\
\text { resonant } \\
\text { freq. }(\mathrm{GHz})\end{array}$ & $\begin{array}{l}\text { Bandwidth } \\
\text { MHz }\end{array}$ \\
\hline $\mathrm{l}_{1}=18$ & -14.13 & 2.53 & $\begin{array}{l}(2.50-2.55 \mathrm{GHz}) \text { is } 50 \mathrm{MHz} \\
(3.77-3.83 \mathrm{GHz}) \text { is } 60 \mathrm{MHz}\end{array}$ \\
& -35.29 & 3.81 & $(6.17-6.61 \mathrm{GHz})$ is $440 \mathrm{MHz}$ \\
\hline & -27.19 & 6.41 & $(2.50-2.55 \mathrm{GHz})$ is $50 \mathrm{MHz}$ \\
$\mathrm{l}_{1}=17.2$ & -14.13 & 2.53 & $(3.82-3.91 \mathrm{GHz})$ is $90 \mathrm{MHz}$ \\
& -17.97 & 3.87 & $(6.25-6.61 \mathrm{GHz})$ is $360 \mathrm{MHz}$ \\
\hline & -24.93 & 6.44 & $(2.50-2.55 \mathrm{GHz})$ is $50 \mathrm{MHz}$ \\
$\mathrm{l}_{1}=16$ & -14.13 & 2.53 & $(3.90-3.91 \mathrm{GHz})$ is $100 \mathrm{MHz}$ \\
& -11.63 & 3.94 & $(6.35-6.63 \mathrm{GHz})$ is $280 \mathrm{MHz}$ \\
\hline
\end{tabular}

From Fig. 14, it can be observed the circle slot parameter sweep has also its influences on the antenna_2 performances. The radius slot of the circle $(r=D / 2)$ is selected to be presented the effects of variation in $r$ on $S_{11}$ shown in Fig. 14. The first frequency band at 6.92 and $7.707 \mathrm{GHz}$ resonances are which respond to any change in the dimensions of the slots by shifting up/down or degrading/ improving the return losses. The analysis reveals that as the radius of a circle $(r=9.2$ and $9.25 \mathrm{~mm}$ ), the wideband characteristic of the antenna represents dual-band at 6.933 and $7.707 \mathrm{GHz}$ the fractional bandwidth increases. While radius value ( $\mathrm{r}=8.5$ and $10 \mathrm{~mm}$ ) the bandwidth decreases. The maximum bandwidth (1.25 $\mathrm{GHz}$ ) of $16 \%$ (from $6.72-7.94 \mathrm{GHz}$ ) resonating frequency at 7.707 GHz, given reflection confections, return loss of $-55 \mathrm{~dB}$ is obtained when $r=9.2 \mathrm{~mm}$ and $-16.92 \mathrm{~dB}$ at $6.93 \mathrm{GHz}$. After the optimization, the parameter of the proposed antennas has the best bandwidth and return loss for a radius value of $r=9.2$ $\mathrm{mm}$. The effects of variation in $\mathrm{r}$ on impedance bandwidth and $\mathrm{S}_{11}$ are tabulated in Table VI.

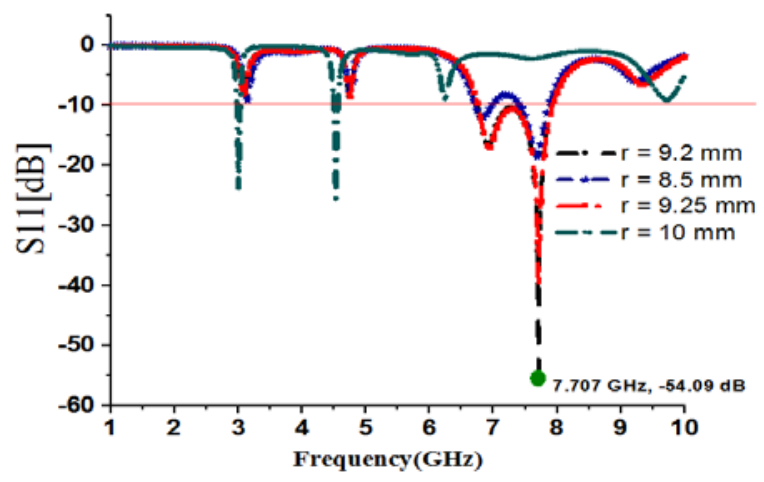

Fig. 14. Simulated $S_{11}$ for Antenna_ 2 for Variation of r. 
TABLE VI. COMPARATIVE RESULTS OF THE RADIUS OF A CIRCLE(R) FOR ANTENNA_2

\begin{tabular}{|l|l|l|l|}
\hline Radius of circle & $\begin{array}{l}\text { Return } \\
\text { loss(dB) }\end{array}$ & $\begin{array}{l}\text { Resonant } \\
\text { freq.(GHz) }\end{array}$ & Bandwidth(MHz), \% \\
\hline $\mathrm{r}=8.5 \mathrm{~mm}$ & -18.60 & 7.68 & $450 \mathrm{MHz}, 6 \%$ \\
& -12 & 6.83 & $260 \mathrm{MHz}, 5 \%$ \\
\hline $\mathrm{r}=9.2 \mathrm{~mm}$ & -55 & 7.707 & $1250 \mathrm{MHz}, 16 \%$ \\
\hline $\mathrm{r}=9.25 \mathrm{~mm}$ & -16.92 & 6.93 & $1170 \mathrm{MHz}, 16 \%$ \\
\hline $\mathrm{r}=10 \mathrm{~mm}$ & -39.60 & 7.69 & $50 \mathrm{MHz}, 2 \%$ \\
& -16.92 & 6.933 & $50 \mathrm{MHz}, 2 \%$ \\
\hline
\end{tabular}

Continue to study the effected of reflection coefficient $\left(\mathrm{S}_{11}\right)$ concerning frequency for proposed microstrip patch antennas with the different substrate material will be shown in Fig. 15. Observed from this figure, the return loss vs frequency response is verified by applied different substrate materials Roger RT5880, FR-4, and Roger RT5870, without changing the dimensions of slots. Whereas, after optimization and from a results acts comparison between them, it is that Roger RT5880 material realized best results of reflection coefficient $(\mathrm{dB})$ and better wider impedance bandwidth respect to these of the other substrate materials used.

\section{E. Comparison with other Studies}

From Table VII, it can be observed analysis comparison between the proposed multiband rectangular microstrip patch and other rectangular antenna structures over previous multiband patch antenna design, such as [4], [5], [6], [7], [8], [9], [10], [15], [19] and [21]. The design recorded in [4-5-6-79-10] the patch antenna work in multi-band frequency, but band-width and gain less than compared with the proposed design. Reference [8-21] in this works antenna operates in single-band therefore, bandwidth, gain and reflection coefficient $\left(\mathrm{S}_{11}\right)$ less than comparing with multiband frequency proposed antenna. The design recorded in [19] the patch operates in dual-band compared with proposed multiband antenna. The objective of this work to design a microstrip patch antenna that operates at multi-band realized high gain and enhanced bandwidth for wireless applications.

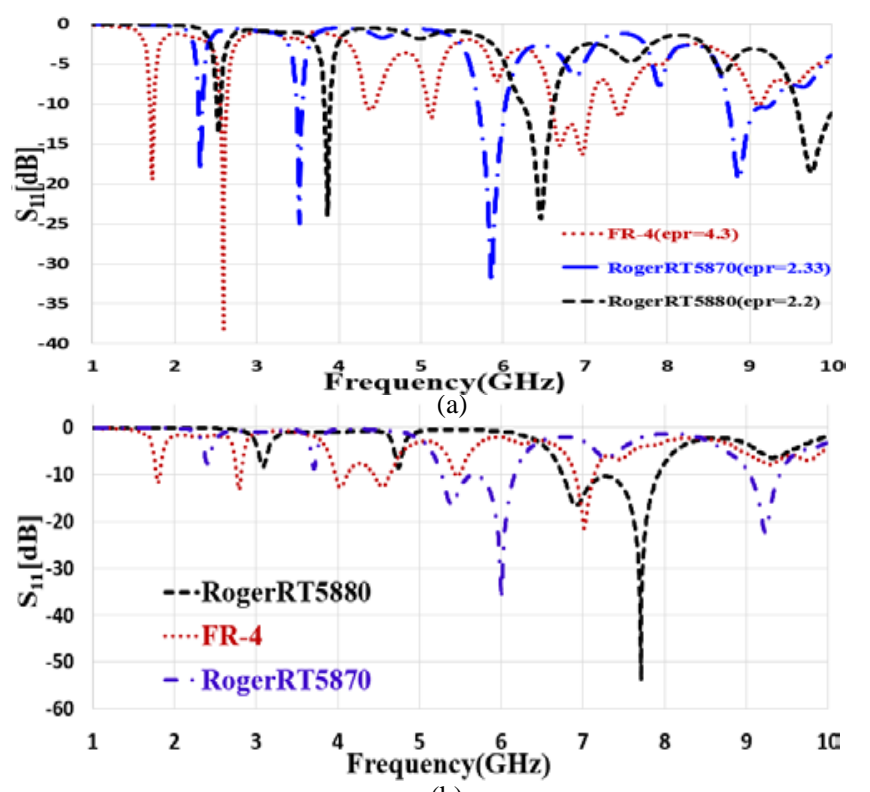

(b)

Fig. 15. Simulated $\mathrm{S}_{11}$ for Various Substrate Materials for given Microstrip Antennas (a) Antenna_1, (b) Antenna_2.

TABLE VII. A COMPARISON BETWEEN THE PROPOSED ANTENNAS WITH OTHER REFERENCE ANTENNAS

\begin{tabular}{|c|c|c|c|c|c|}
\hline Ref. & No. of bands & Sizes $(\mathbf{m m})$ & Resonant frequency $(\mathrm{GHz})$ & Bandwidth (MHZ) & Gain (dB) \\
\hline [4] & Multi-band & $60 \times 55 \times 1.59$ & $4.3,5.0,6.1,7.4,8.9,9.2$ & $\begin{array}{l}\text { 68.6, 126.7, 132, 124.3, } \\
\text { 191.2, 530.6 }\end{array}$ & $\begin{array}{l}1.08,3.23,3.36,2.77,3.07 \text {, } \\
4.87\end{array}$ \\
\hline [5] & Multi-band & $70 \times 70 \times 1.58$ & $\begin{array}{l}1.75,3.65,4.12,5.55,6.5 \text {, } \\
7.77\end{array}$ & $170,60,110,120,140$ & 7.2, 11.2, 11.3, 7, \\
\hline [6] & Multi-band & $46.32 \times 25 \times 1.6$ & $0.45,1.35,1.92,2.57$ & 185, 151, 77, 218 & $4.484,2.59,3.27,4.39$ \\
\hline [7] & Multi-band & $70 \times 60 \times 1.6$ & $1.81,3.6,4.53,5.73$ & $70,290,680$ & $5.71,5.54,5.01,5.32$ \\
\hline [8] & Single-band & $9.5 \times 8 \times 1.6$ & 15 & 1140 & 3.44 \\
\hline [9] & Multi-band & $70 \times 70 \times 1.6$ & $2.313,2.396,2.478$ & $50,60,60$ & $1,1.2,0.7$ \\
\hline [10] & Multi-band & $33.7 \times 33.7 \times 1.6$ & $1.25,1.48,1.8,2.25,2.9$ & $\begin{array}{l}3.2 \%, 3.4 \%, 3.33 \%, 4.5 \% \text {, } \\
3.1 \%\end{array}$ & $1.1,1.12,1.15,1.39,1.4$ \\
\hline [15] & Single-band & $60 \times 50 \times 5$ & 3.8 & UWB & |------------- \\
\hline [19] & Dual-band & $29.52 \times 34.35 \times 1.57$ & 10,60 & 384 & $13.5,13$ \\
\hline [21] & Single-band & $47 \times 39 \times 0.787$ & 2.4 & 25.5 & 6.65 \\
\hline $\begin{array}{l}\text { Proposed } \\
\text { antennas }\end{array}$ & Multi-band & $47 \times 38 \times 3.18$ & $\begin{array}{l}2.45,2.53,3.86,6.45 \\
6.93,7.707\end{array}$ & $\begin{array}{l}70,60,70,410 \\
1420\end{array}$ & $\begin{array}{l}\text { 7.31, 8.18, 7.97, 10.6, 5.56, } \\
6.22\end{array}$ \\
\hline
\end{tabular}




\section{EXPERIMENTAL RESULTS}

The fabricated prototype of two proposed antennas, the first antenna has a tri-band and the second has dual-band frequencies. The proposed patch antennas are fabricated and measured to verify the performance of the proposed multiband microstrip antenna printed on the dielectric constant of 2.2 of Rogers RT5880 substrate with a loss tangent of 0.025 and a $3.18 \mathrm{~mm}$ thickness. a copper layer thick of $0.07 \mathrm{~mm}$ on each side for the patch and ground plane for the proposed microstrip antennas. The front side view and measurement of the proposed antennas are shown in Fig. 16.

The prototype model structure is fabricated at the national telecommunication institute (NTI) Cairo Egypt, while the experimental verification of the $S_{11}$ results and the far-field measurements are carried out using the anechoic chamber at Microwave lab, Ain-Shams University, Cairo Egypt.

The measured return $\operatorname{loss}\left(\mathrm{S}_{11}\right)$, VSWR, realized gain, directivity, and far-field results of antenna_1 and antenna_2 are realized in good agreement with simulation results illustrated in Fig. 17. Fig. 17(a) shows the measured return $\operatorname{loss}\left(\mathrm{S}_{11}\right)$ exhibits good tri-band frequency response, and experimental results verified multi-band frequency. The measured $\mathrm{S}_{11}$ and impedance bandwidth is shown in Table VIII.

The measured impedance bandwidths for antenna_1 are shown in Fig. 17 (a) as (2.36 -2.477 GHz, 5\%) at the 2.402 $\mathrm{GHz},(6.32-6.63 \mathrm{GHz}, 4 \%)$ at the $6.55 \mathrm{GHz}$ band, and (7.077$7.387 \mathrm{GHz}, 4.5 \%$ ) at the $7.25 \mathrm{GHz}$ band.

Fig. 17(b) shows $\mathrm{S}_{11}$ of antenna_2 which exhibits a good dual-band frequency response. The measured $S_{11}$ impedance bandwidth is $1.42 \mathrm{GHz}(6.518-7.949 \mathrm{GHz}, 20 \%)$ at 7.707 $\mathrm{GHz}$, which is better than the simulated bandwidth $(1.25 \mathrm{GHz})$ valid for C-band and X-band for 4G, and suitable for midband 5G wireless applications. The measured results and simulated $\mathrm{S}_{11}$ microstrip are comparisons presented in Table VIII.

The experimental results return loss $\left(\mathrm{S}_{11}\right)$ is in close with its simulation result. However, there, exist some slight discrepancies caused during the implementation of the microstrip patch antenna precision and interface deviation due to loss material, Rogers RT5880 plate for the manufacture of the antenna prototype which is not typical in each country. The fabricated method and measurement techniques generate the differences between simulated and measurement results.
Also, $S_{11}$ levels are accredited to tolerance during the fabricated and measurement steps.

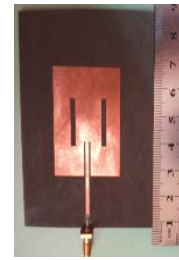

Top view

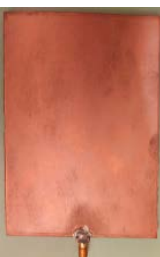

(a) Back view

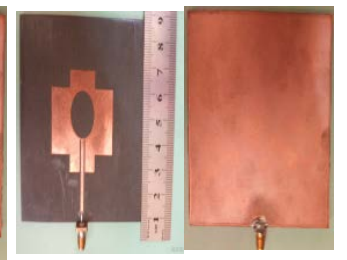

Top view (b) Back view

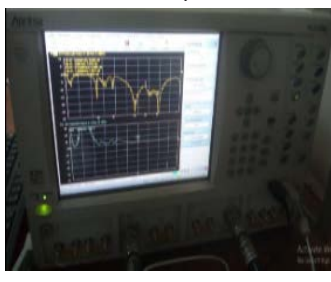

(c)

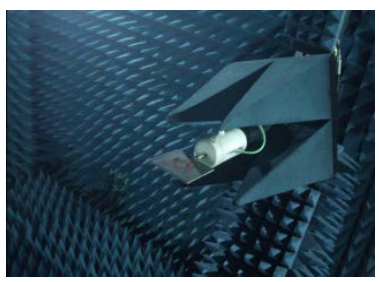

(d)
Fig. 16. Fabrication and Measurement for Proposed Microstrip Patch Antennas, (a) Fabricated Antenna_1 (b) Fabricated Antenna_2 (c) The Proposed Microstrip Patch Antennas Measurement on Network Analyzer (d) Experimental Test which was set up of Proposed Antennas in an Anechoic Chamber.

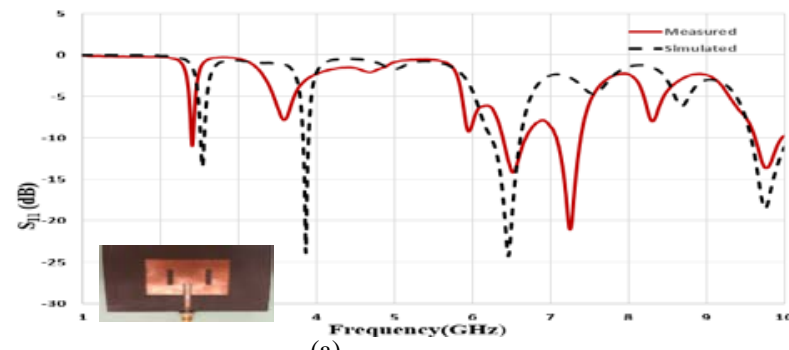

(a)

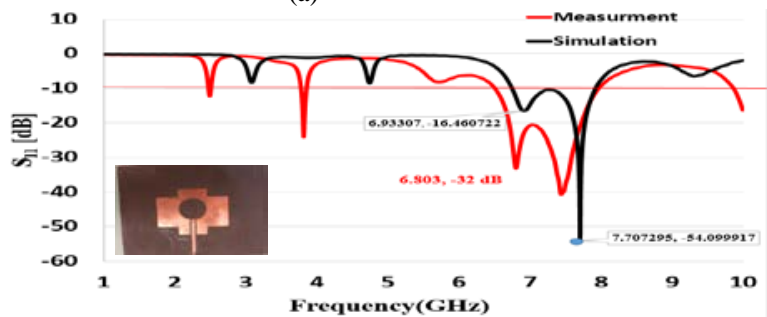

(b)

Fig. 17. Measured and Simulated of Reflection Coefficient $S_{11}$ for (a) antenna_1, (b) antenna_2.

TABLE VIII. The ExPERIMENTAL MEASUREMENT AND Simulated COMPARISOn Results, TRI-BAND OF ANTENNA_1, AND A DuAL-BAND OF ANTENNA_2

\begin{tabular}{|c|c|c|c|c|c|c|c|c|c|}
\hline antenna_1 & $\begin{array}{l}\text { Resonant } \\
\text { freq. } \\
\text { (GHz) }\end{array}$ & $\begin{array}{l}\text { Directivity } \\
\text { (dBi) }\end{array}$ & $\begin{array}{l}\text { Realized } \\
\text { Gain (dB) }\end{array}$ & $\begin{array}{l}\text { Bandwidth } \\
\text { (MHz) }\end{array}$ & antenna_2 & $\begin{array}{l}\text { Resonant } \\
\text { freq. (GHz) }\end{array}$ & $\begin{array}{l}\text { Directivity } \\
\text { (dBi) }\end{array}$ & $\begin{array}{l}\text { Realized } \\
\text { Gain (dB) }\end{array}$ & $\begin{array}{l}\text { Bandwidth } \\
\text { (MHz) }\end{array}$ \\
\hline Measured & $\begin{array}{l}7.25 \\
6.45 \\
2.40\end{array}$ & $\begin{array}{l}12 \\
8.5 \\
8.9\end{array}$ & $\begin{array}{l}9 \\
6.5 \\
7.2 \\
\end{array}$ & $\begin{array}{l}310 \\
240 \\
50\end{array}$ & Measured & $\begin{array}{l}7.44 \\
6.80\end{array}$ & $\begin{array}{l}8.5 \\
6.9\end{array}$ & $\begin{array}{l}6.5 \\
5\end{array}$ & 1420 \\
\hline Simulated & $\begin{array}{l}6.45 \\
3.86 \\
2.53\end{array}$ & $\begin{array}{l}10.62 \\
8.22 \\
8.34\end{array}$ & $\begin{array}{l}10.5 \\
7.97 \\
8.18\end{array}$ & $\begin{array}{l}410 \\
70 \\
50\end{array}$ & Simulated & $\begin{array}{l}7.707 \\
6.93\end{array}$ & $\begin{array}{l}7 \\
6.9\end{array}$ & $\begin{array}{l}6.22 \\
5.56\end{array}$ & 1250 \\
\hline
\end{tabular}


Illustrates the performance of measured VSWR from Fig. 18 , for the proposed patch antennas, which verified value less than 1.5 at all resonant frequencies compared with simulated results. At all frequencies, minimum reflected power is inferior to $-20 \mathrm{~dB}$. The conclusion derived from the analysis of both Fig. 17 and 18, measured results of return loss and VSWR respectively, confirms that the designed multi-band microstrip patch antenna ensures obtaining good performance.

From Fig. 19, it can be observed realized gain plots vs frequency measured and simulated for the antenna_1 and antenna_2. The simulated gain is $10.6 \mathrm{~dB}$ at high frequency $(6.45 \mathrm{GHz})$ and $8 \mathrm{~dB}$ at low frequency $(2.53 \mathrm{GHz})$. The measured gain of $7.2 \mathrm{~dB}$ at $2.402 \mathrm{GHz}$ frequency, while 6.5 $\mathrm{dB}$ at $6.55 \mathrm{GHz}$ frequency is shown in Fig. 19(a).

Fig. 19(b) shows the experimental and simulated result realized gain of antenna_2. The measured gain is $5 \mathrm{~dB}$ at 6.8 $\mathrm{GHz}, 5.6 \mathrm{~dB}$ at $7.44 \mathrm{GHz}$, while the simulated realized gain is 5.56, and 6.22 $\mathrm{dB}$ at 6.93, 7.707 GHz, respectively.

Fig. 20 shows the measured and simulated directivity against frequency for the antenna_1 and antenna_2.

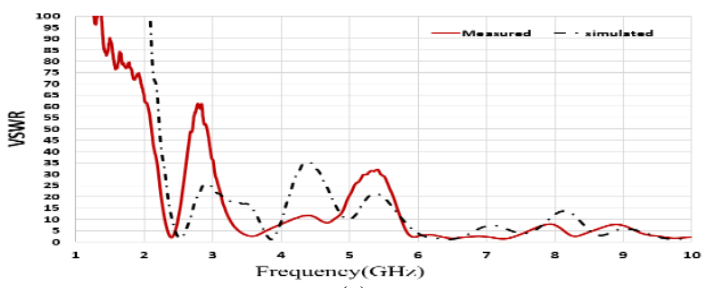

(a)

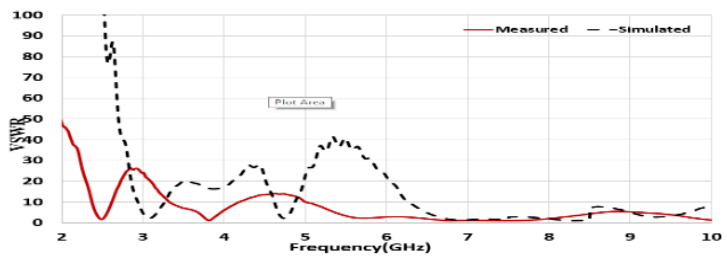

(b)

Fig. 18. VSWR Measured and Simulated for (a) Antenna_1 (b) Antenna_2.

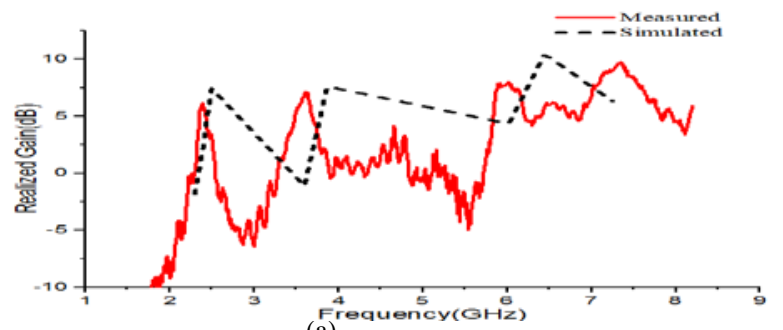

(a)

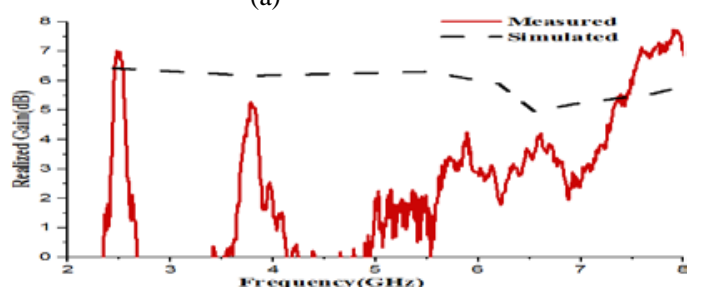

(b)

Fig. 19. Measured and Simulated Realized Gain of (a) for Antenna_1, and (b) for antenna_2.
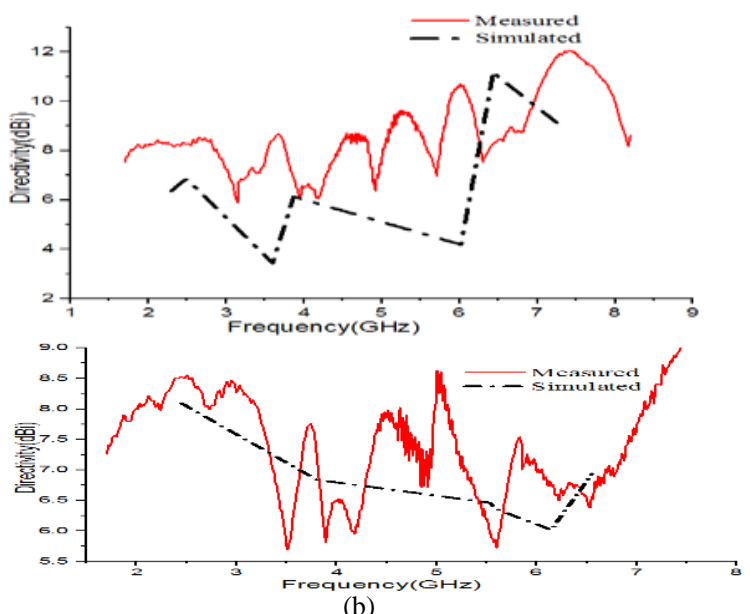

Fig. 20. Measured and Simulated Directivity for (a) Antenna_1, and (b) Antenna_2.

The realized gain, directivity, and impedance bandwidth of proposed antennas are tabulated in Table VIII.

Fig. 21(a), (b) display the experimental measurement and simulation radiation patterns for the antenna_1 along with two elevation cuts (xz and yz planes) exhibit dual-polarization, E and $\mathrm{H}$-plane co and cross-polarization at frequency bands 2.53 and $6.45 \mathrm{GHz}$.

Fig. 22 displays the experimental measurement and simulated radiation patterns for an antenna_2 along with two elevation cuts (xz and yz planes) exhibits dual-polarization, $\mathrm{E}$ and H-plane co, and cross-polarization at $7.707 \mathrm{GHz}$. The deviation of the measured results from the simulated results may be attributed to fabrication imprecision and measurement errors. Besides, the dielectric slab will be cause-effect, with little differences in the side lobes of the radiation patterns between measurements and simulation results.

From Fig. 21 and 22 discussions of co-polarization and cross-polarization between measurement and simulated for proposed antennas. Co-polarization is defined as the polarization the antenna was intended to radiate, while Cross its perpendicular pair [1].

The cross-polar and co-polar in $\mathrm{E}$ and H-plane for antenna_1 have been shown in Fig. 21(a) and Fig. 21(b) at 2.53, $6.45 \mathrm{GHz}$ respectively, which is close to omnidirectional nature. Fig. 21(a) has shown radiation pattern in E-plane, simulated co-polar radiation angular width 27.3 deg. has been measured with an angular width (3) of 25.3 degrees at 6.5 GHz. But simulated cross-polar 39.7 deg. and measured 35.5 deg. at $6.5 \mathrm{GHz}$. While the measured co-polar in E-plane angular width of 68.8 degrees at $2.5 \mathrm{GHz}$ and simulated angular width of $75.0 \mathrm{GHz}$ at $2.53 \mathrm{GHz}$. But radiation pattern in E-plane the measured cross-polar angular width about 58.8 degrees at $2.5 \mathrm{GHz}$ and simulated 76.2 degrees at $2.53 \mathrm{GHz}$.

Fig. 21(b) shows simulated co-polar in H-plane of 68.5 degrees and measured 75.2 degrees at $2.53 \mathrm{GHz}$ whereas, the simulated cross-polar in H-plane angular width 68.8 degrees at $2.5 \mathrm{GHz}$, and measured angular width of 63.4 degrees at 2.5 $\mathrm{GHz}$. 

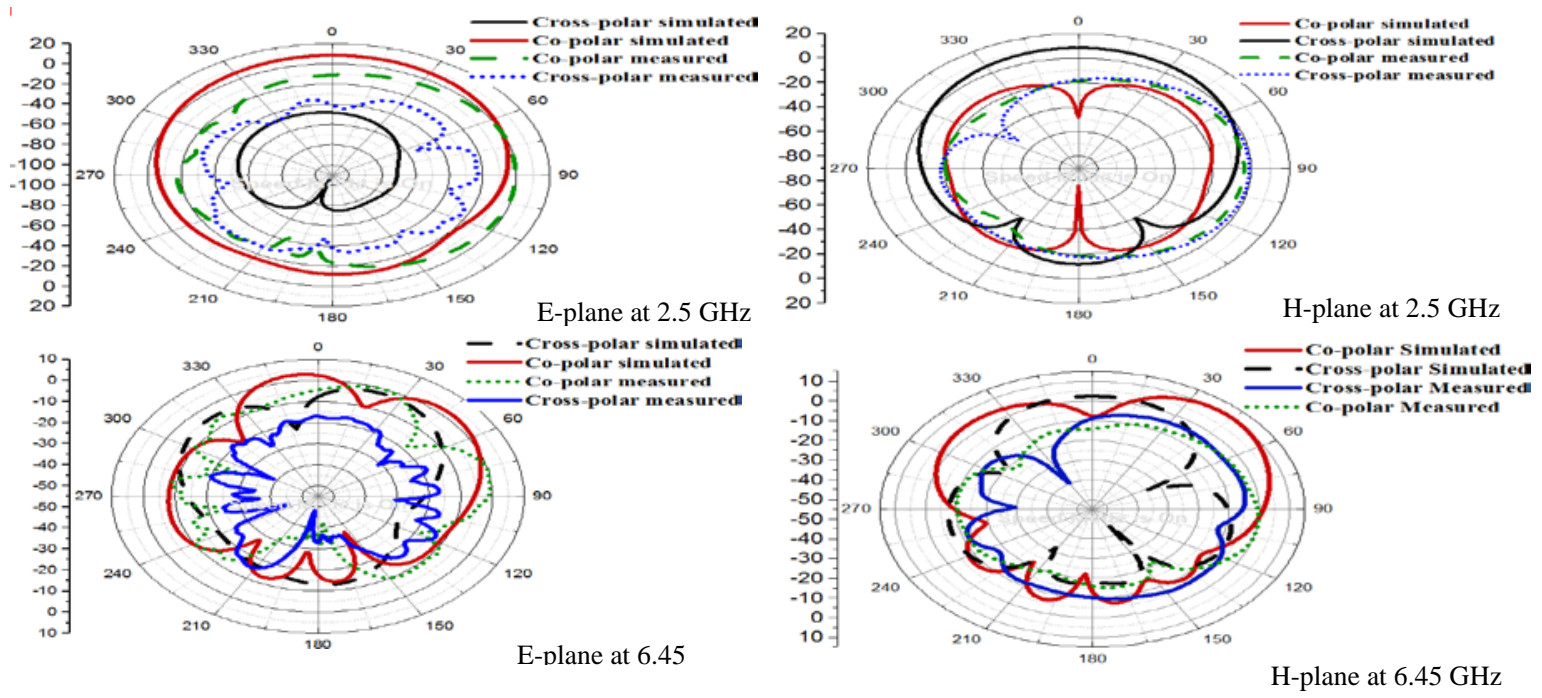

Fig. 21. Measured and Simulated Co-polar and Cross-polar of Antenna_1 at 2.5 and 6.45 GHz.

The simulated cross-polar in H-plane angular width of 58.0 degrees at $6.45 \mathrm{GHz}$ and measured 59.8 degrees at 6.5 $\mathrm{GHz}$. Whereas, simulated co-polar in H-plane of 41.8 degrees at $6.45 \mathrm{GHz}$ and measured of 58.3 degrees at $6.5 \mathrm{GHz}$. It is possible to omission the far-field radiation in E-plane, compared to H-plane at frequency band $2.53 \mathrm{GHz}$, whereas, it is noted that the cross-polarization of the E-plane is lower than the cross-polar in the H-plane. Similarly, the cross-polar in far-field at $6.45 \mathrm{GHz}$ band in the E-plane is lower than the cross-polar in H-plane. Therefore, the angular-width is reduced when the far-field radiation pattern is changed from Omni-to-bidirectional.

Fig. 22 has shown co-polar and cross-polar in the $\mathrm{H}$-and $\mathrm{E}$ plane. Fig. 22(a) illustrated measured a co-polar 74.5 degree and simulated 70.1 degrees at $7.707 \mathrm{GHz}$. Also, a measured cross-polar angular width of 49.7 degrees and simulated angular width of 51.0 degrees at $7.707 \mathrm{GHz}$ has been shown.

Fig. 22(b) shows measured co-polar in H-plane angular width of 54.8 degrees and simulated 58.3 degrees. Also, the cross-polar angular width of 35.2 and 38.3 degrees was measured and simulated respectively at $7.707 \mathrm{GHz}$.

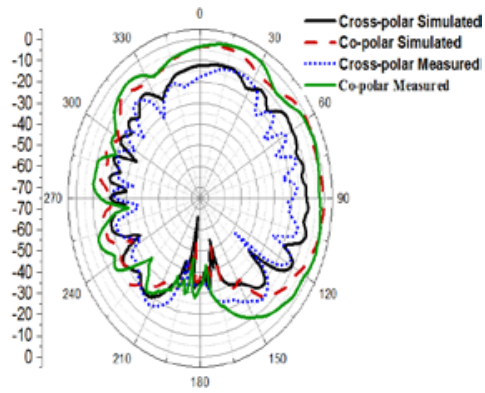

(a)

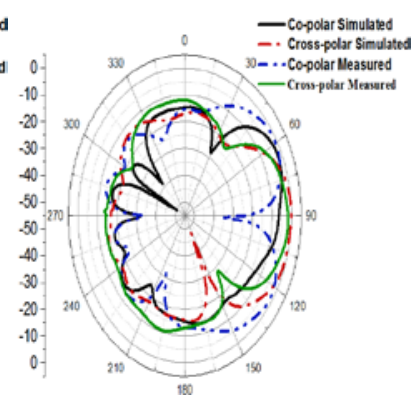

(b)
Fig. 22. Measured and Simulated Co-polar and Cross-polar for Microstrip Antenna_2 at 7.707 GHz, (a) E-plane, (b) H-plane.

\section{CONCLUSION}

In this work, we design and fabricate two proposed microstrip antenna covers multi-band microstrip patch antennas. These proposed antennas cover the useful frequency band of modern wireless communication systems. Antenna_1 covers tri-band frequency, for WiMAX band $2.53 \mathrm{GHz}(2.51-$ $2.55 \mathrm{GHz})$, WLAN/C-band band $3.86 \mathrm{GHz}(3.80-3.87 \mathrm{GHz})$, and C-band $6.45 \mathrm{GHz}(6.19-6.60 \mathrm{GHz})$ which has potential for C-band in 5G services. Antenna_2 covers dual-band for C- band, and X-band 6.92/ 7.707 GHz (6.72 - 7.92 GHz, 1420 $\mathrm{MHz}$ ) which is serving for $\mathrm{C}$ - band and suitable for mid-band 5G application. The proposed design of microstrip patch antennas is characterized as simple structures to be manufactured $\left(94 \times 76 \times 3.18 \mathrm{~mm}^{3}\right)$. Besides, Experimental results verified good conformity with simulation results such as return loss, gain, bandwidth, and radiation pattern of these antennas.

\section{FUTURE WORK}

Simulation the antenna on another simulator and compare the simulation results obtained with two simulators: Improvement the bandwidth and radiation pattern; Fabricated microstrip antennas with other material is low cost.

\section{REFERENCES}

[1] Balanis, “Antenna Theory: Analysis and Design”, John Wiley \& Sons, Inc., Hoboken, New Jersey, February 2016.

[2] D. Pardhan, "Circular patch with circular slit patch the antenna used for ultra-wideband application”, International Journal of Electrical, Electronics and Data Communication, Vol. 5, Issue2, Feb.2017.

[3] A. Gupta, R. Kumar, "A Survey of 5 G network: Architecture and emerging technologies”,2015, IEEE.

[4] M. Gupta and V. Mathur, "Koch boundary on the square patch microstrip antenna for ultra-wideband applications”, Alexandria Eng. Elsevier, 2017.

[5] Roopa, Jayadeva, \& Kumarswamy, "Enhancement of performance parameters of sierpeinsiki antenna using the computational technique", [WiSPNET Conference, 2016].

[6] M. A. Amin, Shimanto and Md. R. Raihan, "Design and Performance Analysis of a multiband microstrip patch antenna for GSM, WiMAX, WLAN, Walkie-Talkie and ATC Application", 5th International Conference on Informatics, Electronics and Vision (ICIEV), IEEE, 2016. 
[7] L. Prasad, B. Ramesh, K.S.R. Kumar, and K.P. Vinay, "Design and implementation of multiband microstrip patch antenna for wireless applications” Advanced Electromagnetics, vol. 7, 2018.

[8] M. H. Reddy, R. M. Joany, G. Manikandan, and A. S. A. Nisha, "Design of microstrip patch antenna with multiple slots for satellite communication", International Conference on Communication and Signal Processing, IEEE, 2017.

[9] T. Dabas, B. K. Kanaujia, D. Gangwar, A. K. Gautam, K. Rambabu, "Design of multiband multi polarized single feed patch antenna" IET Microw. Antennas Propag., Vol. 12 Iss. 15, pp. 2372-2378, 2018.

[10] A. Ghosal, S. Kumar, and A. Das, "Multi-frequency rectangular microstrip antenna with an array of L-slots”, International Journal of Electronics and Communications (AEÜ), Elsevier, 2019.

[11] U. Keskin, B. Döken, and M. Kartal, "Bandwidth improvement in microstrip patch antenna”, IEEE, 2017.

[12] R. Kushwaha, V. K. Singh, N. K. Singh, A. Saxena, and D. Sharma, “A Compact pentagonal textile microstrip antenna for wideband application”, Springer Nature Singapore, Pte Ltd., 2018.

[13] S. Srivastava, D. Somwanshi, "Design and analysis of rectangular microstrip patch antenna for ZigBee application”, IEEE International Symposium on Nanoelectronic and Information Systems, 978-1-46739692-9/15, IEEE, 2015.

[14] Km. Kamakshi, A. Singh, M. Aneesh, J. A. Ansari, "Novel design of microstrip antenna with improved bandwidth”, Hindawi, ID 659592, 7 Pages,2014.

[15] S. K. Hasan, A. C. Shagar, "Design and analysis of U-shaped microstrip patch antenna”, 3rdInternational Conference on Advances in Electrical, Electronics, Information, Communication, and Bio-Informatics (AEEICB17), IEEE, 2017.

[16] Lv. Hong, H. Zhixiang, S. Dengzhi, "Design of a dual-band microstrip antenna”, IEEE, 2016.
[17] N. Agrawal, A. K. Gautam, K. R. Faisa, "Design and packaging of multi-polarized triple-band antenna for automotive applications", International Journal of Electronics and Communications (AEÜ), Elsevier, 2019.

[18] S. Patiland, V. Rohokale, "Multiband smart fractal antenna design for converged 5G wireless networks” International Conference on Pervasive Computing (ICPC), IEEE, 2015.

[19] M. S. Rabbani and H. G. Shiraz, "Improvement of a microstrip patch Antenna gain and bandwidth at $60 \mathrm{GHz}$ and $\mathrm{X}$ bands for wireless applications”, Microwaves, Antenna \& Propagation, IET, vol. 10, 2016.

[20] M. M. Islam, M.T. Islam, and M. R. I. Faruque, "Dual band operation of a microstrip patch antenna on a duroid 5870 substrate for $\mathrm{Ku}-$ and $\mathrm{K}$ bands”, Hindawi, ID378420,10 pages, 2013.

[21] N. A. Muhammad. and Y. Idris, "Design and analysis of microstrip patch antenna for global WLAN applications using Matlab and CST micro-studio software. Vol. 6, Issue no. 4 ISSN 2321 3361, IJESC, 2016

[22] CST Microwave Studio, ver. 2015, Computer Simulation Technology, Framingham, MA, 2015.

[23] Shivnarayan, S. Sharma, B. R Vishvkarma, “Analysis of slot loaded microstrip patch antenna”, Indian Journal of Radio and Space Physics, vol. 34, pp. 424-430, December 2005.

[24] N. M. Tarpara, R. R. Rathwa, D. N. A. Kotak, "Design of slotted microstrip patch antenna for 5G Application”, International Research Journal of Engineering and Technology, vol. 05, 2018.

[25] N. Gupta, "Effects of slots on microstrip patch antenna”, International Research Journal of Engineering and Technology, vol. 04 Issue: 02, 2017.

[26] J. Stewart, C. Nickerson, T. Lewis, "5G Mid-Band spectrum global update”, REF:2020391-62, MARCH 2020.

[27] “Global update on spectrum for 4G \& 5G”, December 2020. 